\title{
Can biomonitors effectively detect airborne benzo $[a]$ pyrene? An evaluation approach using modelling
}

\author{
Nuno Ratola ${ }^{1,2}$ and Pedro Jiménez-Guerrero ${ }^{1}$ \\ ${ }^{1}$ Physics of the Earth, Regional Campus of International Excellence "Campus Mare Nostrum", University of Murcia, \\ Edificio CIOyN, Campus de Espinardo, 30100 Murcia, Spain \\ ${ }^{2}$ LEPABE, Departamento de Engenharia Química, Faculdade de Engenharia da Universidade do Porto, \\ Rua Dr. Roberto Frias, 4200-465 Porto, Portugal
}

Correspondence to: Nuno Ratola (nrneto@um.es)

Received: 29 May 2015 - Published in Atmos. Chem. Phys. Discuss.: 30 September 2015

Revised: 2 March 2016 - Accepted: 15 March 2016 - Published: 5 April 2016

\begin{abstract}
Biomonitoring data available on levels of atmospheric polycyclic aromatic hydrocarbons (PAHs) in pine needles from the Iberian Peninsula were used to estimate air concentrations of benzo $[a]$ pyrene $(\mathrm{BaP})$ and, at the same time, fuelled the comparison with chemistry transport model representations. Simulations with the modelling system WRF+EMEP+CHIMERE were validated against data from the European Monitoring and Evaluation Programme (EMEP) air sampling network. Modelled atmospheric concentrations were used as a consistent reference in order to compare the performance of vegetation-to-air estimating methods. A spatial and temporal resolution of $9 \mathrm{~km}$ and $1 \mathrm{~h}$ was implemented. The field-based database relied on a pine needles sampling scheme comprising 33 sites in Portugal and 37 sites in Spain complemented with the BaP measurements available from the EMEP sites. The ability of pine needles to act as biomonitoring markers for the atmospheric concentrations of $\mathrm{BaP}$ was estimated by converting the levels obtained in pine needles into air concentrations by six different approaches, one of them presenting realistic concentrations when compared to the modelled atmospheric values. The justification for this study is that the gaps still exist in the knowledge of the life cycles of semi-volatile organic compounds (SVOCs), particularly the partition processes between air and vegetation. The strategy followed in this work allows for the effective estimation by the model of concentrations in air and vegetation and of the best approaches to estimate atmospheric levels from values found in vegetation.
\end{abstract}

\section{Introduction}

Semi-volatile organic compounds (SVOCs) are widespread chemicals that even at low concentrations possess carcinogenic capacity (Baussant et al., 2001) and ecotoxicity (Solé, 2000) due to their persistence in different environmental matrices (air, soil, water, living organisms). In particular, polycyclic aromatic hydrocarbons (PAHs) originate from natural and anthropogenic combustion processes or are released from fossil fuels (Mastral and Callén, 2000) and can be transported in the atmosphere over long distances in gaseous phase or as particulate matter (Baek et al., 1991). The lighter PAHs (2 or 3 aromatic rings) exist mainly in the gas phase, whereas the heavier (5 to 6 rings) consist almost entirely of the particulate phase (Bidleman, 1988), and this is the case of 5-ringed benzo $[a]$ pyrene $(\mathrm{BaP})$, arguably the most studied PAH. BaP is the reference for PAH air quality standards, as defined by the European Commission, which sets a limit of $1 \mathrm{ng} \mathrm{m}^{-3}$ over a 1-year averaging period (Directive 2008/50/EC, 2008).

The establishment of strategies for sampling and modelling of SVOCs in the atmosphere aiming at the definition and validation of their spatial, temporal and chemical transport patterns can be achieved by an integrated system of third-generation models that represent the current state of knowledge in air quality modelling and experimental data collected in field campaigns (Jiménez-Guerrero et al., 2008; Morville et al., 2011). The modelling methods currently applied for SVOCs use very simple mass balance techniques or have deterministic approaches, reflecting the complexity 
to characterise adequately the chemical transport processes. These limitations call for more experimentally based information, hence the need to combine field-based campaigns and modelling to address the problem properly (Jakeman et al., 2006), including multi-matrix approaches whenever possible.

Moreover, measurements of pollutants such as PAHs are labour-intensive compared to those of criteria air contaminants such as ozone and particulate matter, and the processes governing their atmospheric fate and representation within chemistry transport models (CTMs) are not yet well understood (Galarneau et al., 2014), particularly in terms of uncertainties associated with the emissions and re-emissions from sinks, partition patterns, volatility and fate of SVOCs, among others. A number of atmospheric modelling studies have tried to characterise the levels and spatial-temporal patterns of PAHs (most of them focusing on BaP) using CTMs both on global (Sehili and Lammel, 2007; Lammel et al., 2009; Friedman and Selin, 2012) and regional scales (Matthias et al., 2009; Aulinger et al., 2011; Bieser et al., 2012; San José et al., 2013). These authors identify a lack of measurement data in Europe to evaluate the behaviour of the CTMs against observations. For example, Bieser et al. (2012) use only six European Monitoring and Evaluation Programme (EMEP) stations (four in the Scandinavian region) and six additional sites in Germany and the UK to evaluate their year 2000 simulations. Bernalte et al. (2012) also highlight the importance of studies on PAHs over the Western Mediterranean (Iberian Peninsula) in order to increase the knowledge of the ambient levels in this region. For that purpose, San José et al. (2013) conducted a 12-week modelling study supported by a field campaign to describe the behaviour of their WRF+CMAQ simulations, but using only a single location in Spain.

Hence, there is a strong need to have trustful information on the atmospheric levels of compounds like $\mathrm{BaP}$ and other SVOCs, in particular in areas with limited information, like over the Iberian Peninsula. In that sense, vegetation species can play a decisive role as biomonitors of the incidence and chemical transport of atmospheric pollutants (Maddalena et al., 2003). Coniferous trees are particularly important, given their worldwide distribution and specific characteristics. However, even if some studies report geographical or temporal patterns of PAHs in coniferous needles (Weiss et al., 2000; Hwang and Wade, 2008; Lehndorff and Schwark, 2009; Augusto et al., 2010; Ratola et al., 2010a, b, 2012; Amigo et al., 2011), only a few deal with their airvegetation distribution (St-Amand et al., 2009a, b). In addition, to our knowledge there is no study regarding the simultaneous use of field and modelling data to assess the distribution of PAHs between air and pine needles. Consequently, if trustful estimates of the atmospheric incidence could be obtained from vegetation, the abundance of biomonitors such as pine needles would provide essential information about the regional and global atmospheric behaviour of persistent contaminants.
Under these premises, the WRF+CHIMERE modelling system, coupled to BaP emission data from EMEP was run and evaluated for the Iberian Peninsula. The modelled depositions were compared to data from biomonitoring campaigns carried out along 70 sites, to assess the ability of the model to reproduce $\mathrm{BaP}$ canopy deposition. Monitoring data from EMEP (Tørseth et al., 2012) was used to validate the modelled atmospheric BaP climatologies (2006-2010). A total of six approaches were tested to estimate the conversion of $\mathrm{BaP}$ levels from vegetation into air. To achieve this, the atmospheric levels from these approaches were evaluated against the modelled air concentrations.

\section{Experimental section}

\subsection{Pine needles sampling}

The Iberian Peninsula, located in the SW of Europe, has an area close to $600000 \mathrm{~km}^{2}$ and a population of almost 60 million, the majority of which distributed along the Atlantic and Mediterranean coastlines, except for some important conurbations such as Madrid, Seville or Zaragoza. Forests (with several pine species commonly present) are scattered through the whole territory. Mountainous areas follow the same trend, with the most elevated chains found in the northern borders (Pyrenees and Cantabria) and in the south (Sierra Nevada). Rural activities can be found almost everywhere, but are particularly important for the economy in the central plateau, where population density is scarcer. A representation of the different land uses in the target domain as represented by the WRF+CHIMERE modelling system can be found in Ratola and Jiménez-Guerrero (2015). In this study, and according to their availability, needles from Pinus pinaster, Pinus pinea, Pinus halepensis and Pinus nigra with up to 1.5 years of exposure to contamination were collected from the bottom and outer branches, placed in sealed plastic bags, kept from light and frozen until extraction. The sampling campaigns were carried out in 33 sites in Portugal and 37 in Spain, in both cases including urban, industrial and rural or remote areas. For further description of these campaigns, the reader is referred to Ratola et al. $(2009,2012)$.

\subsection{Pine needles analysis and quantification}

The analytical procedure used to quantify the levels of PAHs (BaP included) in pine needles was reported previously (Ratola et al., 2009, 2012). A brief description of the methodology and of some characteristics of the pine needles from the different species can be found in the Supplement.

\subsection{Methods for the estimation of BaP air concentrations from vegetation}

Given the lack of information on atmospheric concentrations of $\mathrm{BaP}$ in the sampling sites chosen for this study, an esti- 
mation of those values from data provided by biomonitoring studies with vegetation (coniferous needles in this case) was required. Resorting to literature, six approaches (four of them using the same main calculation method, varying only one parameter) were tried and the resulting estimated BaP concentrations were compared with the modelling experiments.

\subsubsection{Approach 1a}

This approach is based on the studies by St-Amand et al. (2007, 2009a, b), who measured the levels of PBDEs and PAHs in vegetation (Norway spruce needles in this case) and in the surrounding atmosphere (both gas-phase and particulate material) and presented a strategy to estimate the air concentrations from those in vegetation and vice versa. In brief, the atmospheric concentration of SVOCs $\left(C_{\mathrm{a}}\right)$ estimated from the levels in vegetation can be determined by the contribution of particle-bound $\left(C_{\mathrm{p}}\right)$ and gaseous $\left(C_{\mathrm{g}}\right)$ phases. In the case of $\mathrm{BaP}$, being a high molecular weight $\mathrm{PAH}$, the gas-phase contribution is negligible, which means $\phi$ (ratio between particle and particle+gas phases) $\approx 1$ and $C_{\mathrm{a}}$ can be given by

$C_{\mathrm{a}}=C_{\mathrm{p}}=\left(C_{v_{\mathrm{p}}} \cdot m\right) /\left(A \cdot v_{\mathrm{p}} \cdot t\right)$,

where $C_{v_{\mathrm{p}}}$ - contribution of particle-bound deposition processes to the total concentration in vegetation $\left(\mathrm{ng} \mathrm{g}^{-1}\right) ; \mathrm{m}$ - dry weight of pine needles ( $\mathrm{g})$; A - total surface area $\left(\mathrm{m}^{2}\right)$ of vegetation (in our study, pine needles); $v_{\mathrm{p}}$ - particle-bound deposition velocity $\left(\mathrm{m} \mathrm{h}^{-1}\right) ; t$ - environmental exposure time of pine needles (h) with $\mathrm{Cp}$ expressed in $\mathrm{ng} \mathrm{m}^{-3}$. Since it was impossible to calculate $v_{\mathrm{p}}$ for our samples, due to the lack of information on the atmospheric concentrations, in this first approach the value calculated by St-Amand et al. (2009a) for Norway spruce (Picea abies) needles was used: $10.8 \mathrm{~m} \mathrm{~h}^{-1}$. Values of the mass and total surface area for the pine needles studied are presented in Table S1 in the Supplement. The exposure time was estimated considering that the new needles sprung out on 15 April and counting the hours from this day to the sampling date.

\subsubsection{Approaches 1b, 1c, and 1d}

These approaches follow the same strategy, only with different $v_{\mathrm{p}}$ values calculated from studies in literature reporting $\mathrm{BaP}$ concentrations in air and pine needles (from $\mathrm{Pi}$ nus sylvestris trees in cases $1 \mathrm{~b}$ and $1 \mathrm{c}$ and a coniferous forest in 1d). Approach $1 \mathrm{~b}$ refers to the work by Klánová et al. (2009) and the estimated $v_{\mathrm{p}}(\mathrm{BaP})$ is $0.0039 \mathrm{~m} \mathrm{~h}^{-1}$, while approach 1c comes from the work by Tremolada et al. (1996), with $v_{\mathrm{p}}(\mathrm{BaP})=0.0263 \mathrm{~m} \mathrm{~h}^{-1}$. For the $1 \mathrm{~d}$ approach, it was considered the deposition velocity Horstmann and McLachlan (1998) found for BaP over a coniferous forest canopy: $2.196 \mathrm{~m} \mathrm{~h}^{-1}$. As can be seen, the variability of $v_{\mathrm{p}}$ is evident, not only considering different species of vegetation, but also using the same species in different locations. In the case of approaches 1b and 1c, Klánová et al. (2009) sampled remote areas whereas Tremolada et al. (1996) considered more urbanised locations, which may justify the higher deposition velocity in the latter case. Differences in the uptake of PAH by different pine species in the same sampling sites are also described in literature (Piccardo et al., 2005; Ratola et al., 2011).

\subsubsection{Approach 2}

This approach follows the work of Tomashuk (2010), which used biomonitoring results in Pinus nigra needles and in turn profits from a study by Simonich and Hites (1994). In the latter, an air-vegetation partition coefficient $\left(K_{\mathrm{v}}\right)$ is defined by

$\ln K_{\mathrm{v}}=(1000 / T) \cdot$ slope -35.95,

with $T$ - air temperature (K); slope - calculated by Simonich and Hites (1994) for some PAHs. And from $K_{\mathrm{v}}$, the air concentration of PAHs $\left(C_{\mathrm{a}}\right)$ can be estimated by (in $\mathrm{ng} \mathrm{m}^{-3}$ )

$C_{\mathrm{a}}=C_{\mathrm{v}} /\left(K_{\mathrm{v}} \cdot\right.$ lipid $)$,

with $C_{\mathrm{v}}$ - concentration in the vegetation $\left(\mathrm{ng} \mathrm{g}^{-1}, \mathrm{dw}\right)$; lipid - lipid content per dry weight of pine needles $\left(\mathrm{mg} \mathrm{g}^{-1}, \mathrm{dw}\right)$. Values of the lipid content for the pine needles studied are presented in Supplement Table S1.

\subsubsection{Approach 3}

Chun (2011) measured PAH concentrations in Pinus koraiensis needles and the surrounding air and came up with the following correlation between $\log K_{\mathrm{oa}}$ and $C_{\mathrm{v}} / C_{\mathrm{a}}$ :

From acenaphthylene to chrysene:

$C_{\mathrm{a}}=C_{\mathrm{v}} / \exp \left[\left(\log K_{\mathrm{oa}}-7.9603\right) / 0.4557\right]$,

with $C_{\mathrm{a}}$ - concentration in air $\left(\mathrm{ng} \mathrm{m}^{-3}, \mathrm{dw}\right) ; C_{\mathrm{v}}$ - concentration in the vegetation $\left(\mathrm{ng} \mathrm{g}^{-1}, \mathrm{dw}\right)$.

From chrysene to benzo(ghi)perylene (the equation used to calculate $\mathrm{BaP}$ concentrations):

$C_{\mathrm{a}}=C_{\mathrm{v}} / \exp \left[\left(\log K_{\mathrm{oa}}-12.18\right) /(-0.2272)\right]$,

$\log K_{\mathrm{oa}}$ is a temperature-dependent coefficient, and was calculated using the following equation:

$\log K_{\text {oa }}=A+(B / T)$,

where coefficients $A$ and $B$ are given by Odabasi et al. (2006) and the temperature $(T)$ in each site was the mean from the 3 months previous to sample collection, since it corresponded to the intervals of exposure between campaigns (with a seasonal periodicity for most sampling points). The equilibrium between air and pine needles is still not completely understood and can be a slow process for compounds with high log $K_{\text {oa }}$ such as BaP (Mackay, 1991); and it may not be possible to acknowledge if "non-equilibrium" conditions or alternative processes occur (Tremolada et al., 1996). 


\subsection{Modelling experiment and validation}

In this study, the Weather Research and Forecasting (WRF) (Skamarock et al., 2008) and the CHIMERE modelling system (Menut et al., 2013), with a resolution of $9 \mathrm{~km}$ for the entire Iberian Peninsula coupled to EMEP BaP emissions (Vestreng et al., 2009), was run and evaluated for the Iberian Peninsula in a simulation covering the years 2006 to 2010 on an hourly basis. This CHIMERE version has been modified to include gaseous and particulate BaP. Gas-phase degradation by $\mathrm{OH}$ radicals, which represents over $99 \%$ of the degradation path for gas-phase $\mathrm{BaP}$, was accounted for, with a $k_{\mathrm{OH}}=5.68 \times 10^{-11}$ (Schwarzenbach et al., 2003). But more importantly, the oxidation of particulate $\mathrm{BaP}$ with ozone was also included, since the respective reaction rate is one order of magnitude higher than other degradation processes, and can be considered the only effective degradation path for particulate $\mathrm{BaP}$ in the atmosphere (Bieser et al., 2012). In this case, the reaction constant follows the approach of Pöschl et al. (2001):

$k=k_{\max }\left[\mathrm{O}_{3}\right] /\left(1+K_{\mathrm{O}_{3}}\left[\mathrm{O}_{3}\right]\right)$,

being $k_{\max }=0.015 \mathrm{~s}^{-1}$ and $K_{\mathrm{O}_{3}}=2.8 \times 10^{-13} \mathrm{~cm}^{3}$. A bias adjustment technique was applied and is referred to in the Supplement, together with a description of the modelling setup and validation procedures (Table S2). All modelled concentrations presented in this work are bias-adjusted.

The $\mathrm{BaP}$ concentrations in pine needles used in this work are taken from biomonitoring campaigns previously performed in the Iberian Peninsula (Ratola et al., 2009, 2010a, b, 2012). These data were compared to the deposition over vegetal canopies as estimated by the CHIMERE transport model. The dry deposition flux in CHIMERE is directly proportional to the local concentration $\mathrm{C}$ of the target compound (in this case, $\mathrm{BaP})$ :

$F=-v_{\mathrm{d}} \cdot C$,

where $F$ represents the vertical dry deposition flux, the amount of material depositing to a unit surface area per unit time. The proportional constant between flux and concentration, $v_{\mathrm{d}}$, is known as the deposition velocity. The main factors governing dry deposition are the grade of the atmospheric turbulence, the chemical properties of the species, and the nature of the soil and the vegetation.

The deposition over vegetal canopies in CHIMERE for particles employs a resistance scheme (Wesely, 1989). The dry deposition velocity follows the formulation of Seinfeld and Pandis (1997):

$v_{\mathrm{d}}=\left(1 /\left(r_{\mathrm{a}}+r_{\mathrm{b}}+r_{\mathrm{a}} \cdot r_{\mathrm{b}} \cdot v_{\mathrm{s}}\right)\right)+v_{\mathrm{s}}$,

where $r_{\mathrm{a}}$ is the aerodynamic resistance (or aerodynamic drag) and $r_{\mathrm{b}}$ the resistance at the quasi-laminar sublayer. The aerodynamics resistance is calculated as the integral of the inverse of the diffusivity coefficient $K_{z}$ up to the middle of the model surface layer, which can be estimated using the analytical formulae of the surface-layer similarity profiles for $K$ (Seinfeld and Pandis, 1997) and $v_{\mathrm{s}}$ stands for the sedimentation velocity. For vegetal canopies, as in our case, corrections have been implemented. These corrections are not detailed in the CHIMERE manual (http://www.lmd.polytechnique.fr/ chimere/), but rather supported on the literature presented (Giorgi, 1986; Peters and Eiden, 1992; Zhang et al., 2001). For this reason, and for the sake of brevity, the same strategy is adopted here and readers are referred to those works for further details.

\section{Results and discussion}

\subsection{Model evaluation for vegetation and air levels}

The model climatologies for BaP in canopy deposition and air concentration were done under the premise of constituting a base for a broad spectrum of studies within the airvegetation interactions. In fact, a description of these simulations was mentioned previously by Ratola and JiménezGuerrero (2015). However, given the importance for the current study, a summary is presented here, also considering a different perspective.

\subsubsection{Vegetation}

The modelled deposition over vegetal canopies was evaluated against observations compiled from pine needles. Thus, the adequacy of the model's deposition velocity for the Iberian Peninsula is assessed by a direct evaluation of the deposition velocity against observations. This information is summarised in Table 1 and a point-to-point comparison is shown in the Supplement (Table S3). The samples were explicitly compared with the model period corresponding to their effective exposure interval. Given the assumption that there is a full uptake by the pine needles of the deposited $\mathrm{BaP}$, the modelled deposition flux is converted to pine needles concentration multiplying it by the respective time of exposure (equivalent for the model and the pine needles). The results indicate an overall good ability of the model to reproduce the vegetation's uptake of BaP, when compared to the biomonitors. Generally, the modelled concentrations tend to be overpredicted DJF, MAM and SON, when the deposited $\mathrm{BaP}$ is overestimated by 0.08 to $0.17 \mathrm{ng} \mathrm{g}^{-1}$ (MFB up to $+17 \%$ ). On the other hand, in summer (JJA) the model is likely to underpredict the measured levels in vegetation $\left(-0.41 \mathrm{ng} \mathrm{g}^{-1},-39 \%\right.$ as MFB), seemingly due to its tendency to volatilise SVOCs as a result of the high temperatures simulated over the Iberian Peninsula. The RMSE remains under $1.5 \mathrm{ng} \mathrm{g}^{-1}$ in all seasons (Table 1), indicating a close approach of the model to the levels obtained in pine needles. Particularly noticeable is the accurate reproduction of the spatial patterns. In fact, the estimates from the spatial correlation coefficient (which is highest for MAM and lowest 

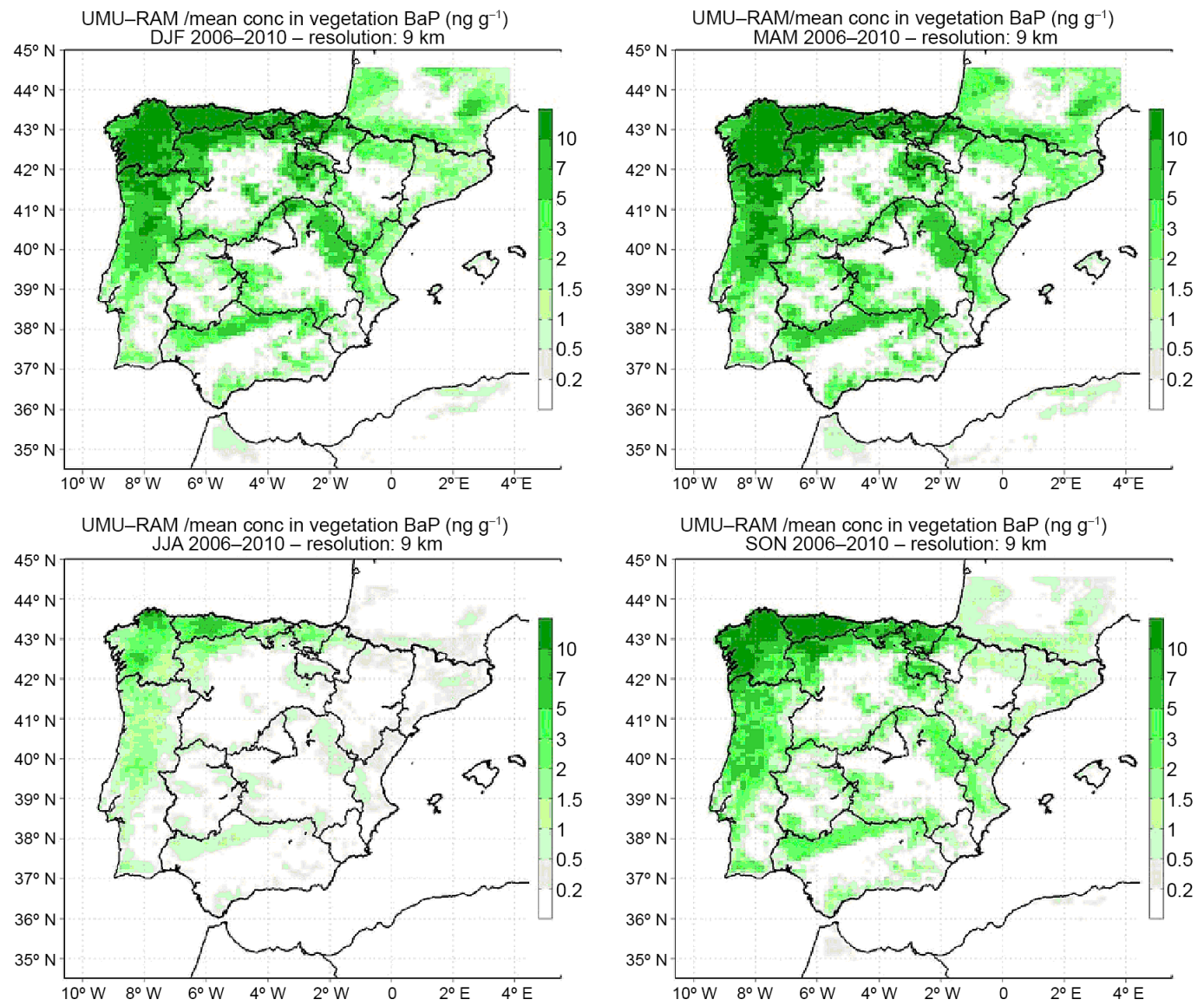

Figure 1. Seasonal distribution of modelled deposition of $\mathrm{BaP}$ on vegetation ( $\mathrm{ng} \mathrm{g}^{-1}$ ) over the domain covering the Iberian Peninsula: (from top-down and left-right): winter (DJF), spring (MAM), summer (JJA), and autumn (SON) climatologies for the period $2006-2010$.

Table 1. Seasonal evaluation of WRF + CHIMERE modelled BaP depositions results (over vegetal canopies) against measured concentrations found in pine needles.

\begin{tabular}{|c|c|c|c|c|}
\hline & DJF & MAM & JJA & SON \\
\hline MFB $(\%)$ & -2.17 & 16.77 & -39.23 & 5.28 \\
\hline $\operatorname{RMSE}\left(\mathrm{ng} \mathrm{g}^{-1}\right.$ ) & 1.26 & 1.45 & 0.84 & 1.97 \\
\hline BIAS $\left(\operatorname{ng~g}^{-1}\right)$ & 0.10 & 0.08 & -0.41 & 0.17 \\
\hline $\mathrm{OBS} \operatorname{MEAN} \pm \mathrm{SD}\left(\mathrm{ng} \mathrm{g}^{-1}\right)$ & $1.67 \pm 1.66$ & $2.39 \pm 2.17$ & $1.25 \pm 0.90$ & $1.85 \pm 1.64$ \\
\hline MOD MEAN $\left(\operatorname{ng~g}^{-1}\right)$ & $1.76 \pm 1.70$ & $2.48 \pm 2.37$ & $0.84 \pm 0.64$ & $2.02 \pm 1.42$ \\
\hline SPATIAL CORR COEF $(r)$ & 0.86 & 0.87 & 0.85 & 0.77 \\
\hline
\end{tabular}

DJF - December, January and February; MAM - March, April and May; JJA - June, July and August; SON September, October and November; MFB - mean fractional bias; RMSE - root mean square error; OBS - pine needle concentrations; SD - standard deviation; MOD - modelled concentrations; CORR COEF - correlation coefficient.

for SON, ranging from 0.77 to 0.87 for all seasons) indicate that regardless of the model bias, the spatial reproducibility of the deposition patterns over the Iberian Peninsula is very well reproduced in all seasons, capturing also the seasonal distribution.

In terms of the modelled levels in canopies, Fig. 1 shows that the deposition of $\mathrm{BaP}$ is clearly lowest for JJA (un- der $3 \mathrm{ng} \mathrm{g}^{-1}$ over most of the Iberian Peninsula) and has the highest values in DJF and MAM (10-20 $\mathrm{ng} \mathrm{g}^{-1}$ over the north-western Iberian Peninsula and the Cantabria coast). But apart from the geographic distribution being closely related to the emitting areas, the differences in the entrapment of PAHs by the different land uses can play an equally significant role, as observed in the spatial uptake patterns 
shown in Fig. 1. Even if a discussion on the role of the different pine species is beyond the scope of this work, several points were brought to our attention. For instance, it was shown previously that $P$. pinaster needles have a superior uptake capacity towards PAHs than $P$. pinea (Ratola et al., 2011) or P. nigra ones (Piccardo et al., 2005). The first two species have a strong implantation in the forests of the Iberian Peninsula, but while $P$. pinea is more equally distributed (although mainly present in the south and Mediterranean coast), P. pinaster prevails in the north-west and Atlantic coast. This may be the reason why the model tends to present higher deviations over the northernmost biomonitoring points $(P$. pinaster, $\mathrm{MFB}=21 \%$ ) than over easternsouthern areas, with predominant $P$. pinea $(\mathrm{MFB}=-17 \%)$, as shown in Table S3). It was also suggested that leaf surface properties are more a function of the environmental exposure than of the plant response (Cape et al., 1989). Given all these facts, both chemistry transport models and other parameterisations face a huge task to represent the levels of pollutants in vegetation. In this sense, enhancing the field experimental work on the uptake of these chemicals would be strongly beneficial.

\subsubsection{BaP air climatology}

As mentioned previously, studies in literature regarding the field monitoring of PAHs levels in the Iberian Peninsula's vegetation are limited and, therefore, modelling strategies can represent a valuable tool to assess BaP levels over the target region. The few existing studies (described in Introduction) reflect two main points: the influence of local sources and the variability of the uptake abilities of the different vegetation species. Since the main focus of this work is on the climatologies of the atmospheric BaP levels, in order to assess the correct reproducibility of their spatial-temporal patterns the WRF+CHIMERE BaP modelled concentrations were evaluated against EMEP air quality data after the bias adjustment explained in the Supplement.

According to Ratola and Jiménez-Guerrero (2015), the modelled atmospheric concentrations of $\mathrm{BaP}$ present normalised biases that are under $30 \%$ over all the EMEP stations in the Iberian Peninsula. The fact that both positive and negative biases were found for annual mean concentrations indicates that the model is not generally inclined towards overprediction or underprediction for all the domain of study. As depicted in Fig. 2, the deviations only range between $+1.63 \mathrm{pg} \mathrm{m}^{-3}$ over the northern Iberian Plateau (Peñausende station, close to the Spanish-Portuguese border) and $-4.59 \mathrm{pg} \mathrm{m}^{-3}$ (San Pablo de los Montes station, in the southern-central Iberian Plateau). The low biases obtained indicate that the model is reproducing accurately the atmospheric concentrations of $\mathrm{BaP}$, and therefore can be used as a reference for the comparison with the levels of this compound obtained from air-vegetation partition, as will be explained in detail below.

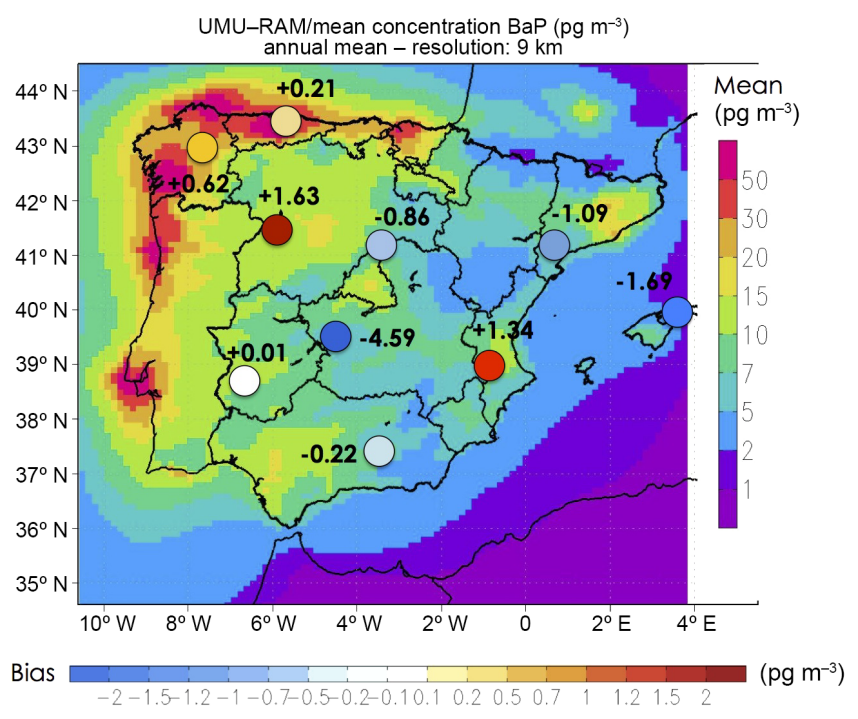

Figure 2. BaP annual mean concentrations $\left(\mathrm{pg} \mathrm{m}^{-3}\right.$, shaded) and biases for EMEP stations ( $\mathrm{pg} \mathrm{m}^{-3}$, circles) using the available information for the period 2006-2010.

Modelled BaP concentrations in the atmosphere (Fig. 3) achieve a maximum during the winter months (DJF), and can reach over $300 \mathrm{pg} \mathrm{m}^{-3}$ in most polluted areas (NW Spain and western coast of Portugal), while background areas hardly exceed $5 \mathrm{pg} \mathrm{m}^{-3}$ (lowest concentrations in the SE Levantine coast). The highest $\mathrm{BaP}$ concentrations measured using pine needles as the biomonitoring matrix and atmospheric concentrations simulated by the model were found in urban and industrial settings, mainly distributed along the northwestern coast of the Iberian Peninsula (as also reported by Amigo et al. (2011) and Ratola et al., 2012) followed by rural and remote areas. This reflects the accumulation of anthropogenic sources like traffic, building heating or industrial processes involving combustions in the most populated areas of the Iberian Peninsula. Due to the characteristics of such sources, a tendency to seasonality can be anticipated as well. In the colder months, traffic and building heating are increased and this is not only reflected by the field measurements (Ratola et al., 2010a), but also by the models, as shown in Fig. 3.

Given that the model represents accurately the air climatologies of $\mathrm{BaP}$, can we use its results to evaluate the ability of the air and/or vegetation methods available in scientific literature to estimate the atmospheric levels of $\mathrm{BaP}$ from biomonitoring databases? Having the accuracy of the model to capture the air concentrations evaluated against EMEP air measurements, the argument this work adopts is the following: since the model correctly captures air concentrations and deposition (which have been previously assessed in Sect. 3.1.1), we can use the modelled air concentrations as a reference to evaluate the fitness of the different vegetation-air conversion approaches. Therefore, in the following section, 

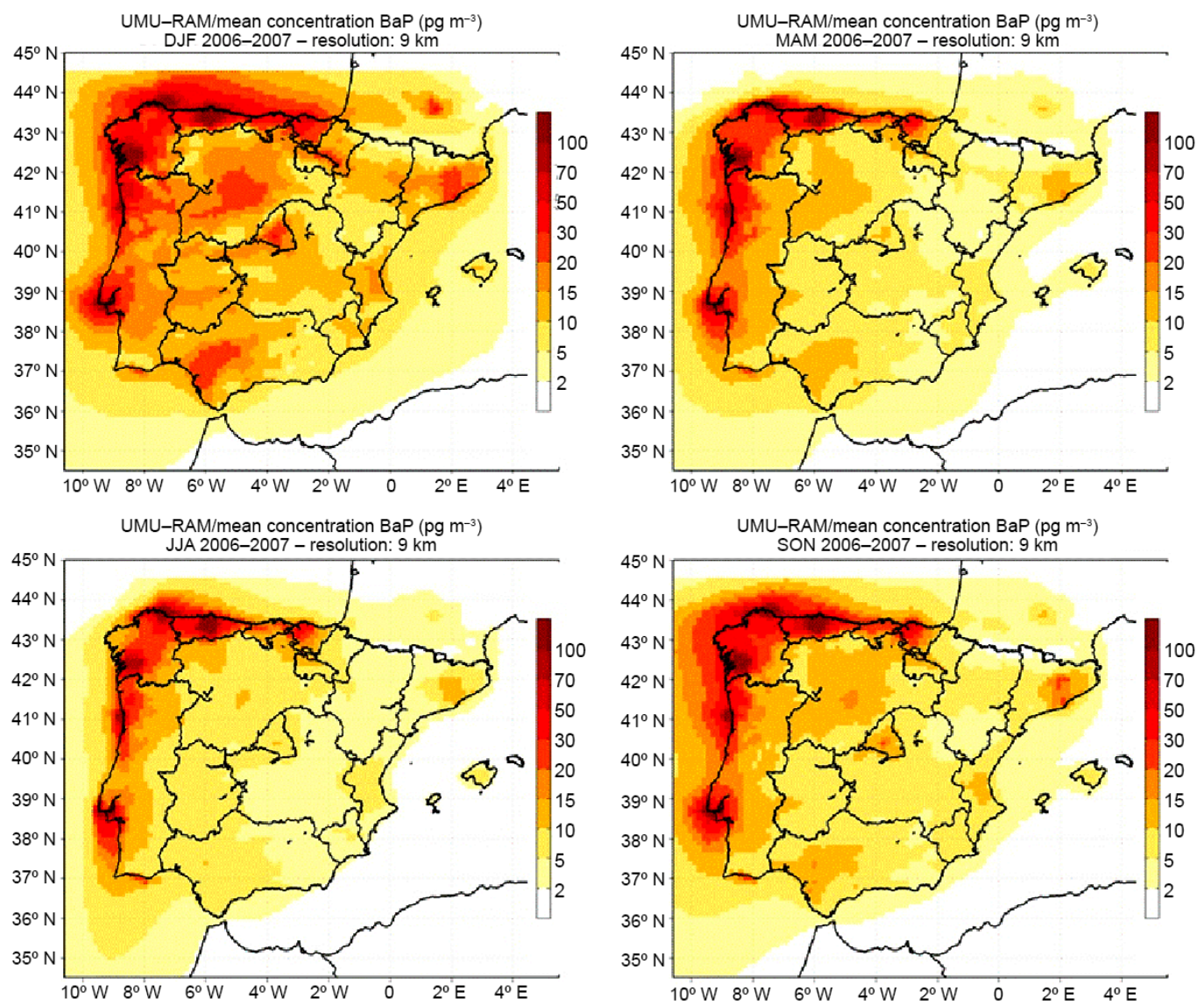

Figure 3. BaP climatologies $\left(\mathrm{pg} \mathrm{m}^{-3}\right.$ ) over the Iberian Peninsula (from top-down and left-right): winter (DJF), spring (MAM), summer (JJA) and autumn (SON) for the period 2006-2010.

the model concentrations have been considered as a consistent reference (due to the low biases obtained) to act as a reference to validate the approaches for this vegetation-to-air conversion.

\subsection{Comparison of vegetation-to-air approaches}

Databases on the atmospheric levels of SVOCs are already available, but the existing ones (like EMEP) do not cover, for instance, the entire Iberian Peninsula for a climatologically representative period of time (apart from some isolated measurements). In terms of vegetation, the scenario is even worse, but since the presence of SVOCs in such environmental matrices (and in particular in pine needles) reflects entirely an entrapment from the atmosphere (Hwang and Wade, 2008), these measured data can be used not only to validate the model results in vegetation but also to complement the information gathered by the direct atmospheric sampling. For that purpose, six approaches to convert the concentrations found in the 70 sites where pine needles were collected into atmospheric levels were compared to the reference provided by the CTM simulations. This hypothesis is based on the fact that models represent correctly the measured atmospheric concentrations of $\mathrm{BaP}$ over the Iberian Peninsula, taking into account the evaluation against EMEP field measurements available. This hypothesis was forced by the lack of simultaneous samplings of vegetation and air concentrations over the target area. Therefore, we used the following methodology: (a) validate simulations with WRF+CHIMERE data against EMEP network measurements, in order to check the ability of the CTM to reproduce atmospheric concentrations over the entire Iberian Peninsula; (b) once proven that errors are acceptable and that the model shows no trend bias, we use modelled atmospheric concentrations as a consistent reference that allows us to compare various vegetation-to-air estimating methods and check which is the most suitable approach for the particular conditions of the area.

It is clear that given the numerous variables and conditions involved, the uptake processes of compounds like PAHs by matrices such as pine needles are not entirely understood (Barber et al., 2004). But the information we have so far indicates that pine needles are valid biomonitors of atmospheric loads, but also can be used to assess the performance of different methods to convert vegetation uptake levels into atmospheric concentrations. Thus, the objective is to test the 
response of the six vegetation-to-air approaches detailed in Sect. 2.3 through a field and/or model check in the sampling points chosen.

Results (Table 2) reveal that approach 1d is the best fit to convert the levels measured in vegetation into air concentrations, when compared to the outcome provided by the model. This approach was used by Ratola and JiménezGuerrero (2015) to assess differences between pine species in modelling simulations as the deposition velocity is in this case defined for an entire forest canopy and not for a given species. This general characteristic is seemingly giving this approach an advantage in terms of the vegetation-to-air calculations. The MFB ranges from $-19 \%$ for spring (MAM) to a slight overestimation during winter (DJF, $+9 \%$ ), being the biases under $3 \mathrm{pg} \mathrm{m}^{-3}$ for all seasons. These errors are relatively low bearing in mind the diversity of the sampling sites considered in this work. Previous works have demonstrated the seasonal variability of PAHs uptake by pine needles (Hwang and Wade, 2008; Ratola et al., 2010a), with the highest levels occurring in winter and the lowest in summer. However, these differences are much more visible in the lighter PAHs (the ones in the gas-phase), given the stronger affinity of the pine needles waxy layer towards their entrapment, when compared to the particulate PAHs.

Being one of the latter, $\mathrm{BaP}$ in pine needles may not experience the same level of seasonal variation as in the atmosphere, even if it presents a similar trend. These seasonal differences can be much stronger in the atmosphere, due to the fluctuation of the emission rates from winter to summer. It is then not surprising that the model underestimates the atmospheric concentrations of $\mathrm{BaP}$ measured in the colder months and overestimates them in the warmer ones, since in this case the field values are obtained from the levels found in the pine needles. Approach 1d is also the best representation for this seasonal variability (estimated as the standard deviation between approaches and the CTM). Additionally, this approach shows the best air-vegetation relationship simulated by the model, with the rest of the methods providing unrealistic concentrations when compared to the measurements in EMEP stations and modelling results. In fact, approaches $1 \mathrm{a}$ and 2 tend to underestimate the modelled concentrations by a factor up to 10 , yielding negative biases for all seasons. The rest of the approaches greatly overestimate the levels of $\mathrm{BaP}$ (by a factor of 100 in the case of $1 \mathrm{c}$ and 3 and of 1000 in approach $1 \mathrm{~b}$ ). These large variations are mainly caused by the difference in the deposition velocities used in each approaches $1 \mathrm{a}$ to $1 \mathrm{~d}$ (from $10.8 \mathrm{~m} \mathrm{~h}^{-1}$ in 1 a to $0.0039 \mathrm{~m} \mathrm{~h}^{-1}$ in $1 b)$ and in completely different vegetation-to-air estimation strategies in approaches 2 and 3. The deposition velocity has an important role in one of the three methodologies for estimating air concentrations from vegetation (methodology which derives into approaches 1a to 1d), but it allows precisely to understand the differences that may occur when conditions are changed (different species, different locations, different times of the year in the same locations, different affecting sources, etc.).

With respect to the temporal correlation coefficients, approaches $1 \mathrm{a}$ to $1 \mathrm{~d}$ present the same value $(0.51)$, as they rely on the same calculations (only changing the deposition velocity). This is an acceptable description of the temporal variability observed in all sites. Approach 2 is not able to reproduce these time series (correlation coefficient of -0.55 ), but, interestingly, it is approach 3 that presents the best correlation (0.80). In this latter case, although the bias for the $\mathrm{BaP}$ concentrations is quite high, the $r$ value can be related with the different uptake efficiencies pine needles show for gasphase or particulate PAHs. The two equations suggested by Chun (2011) to relate concentrations of PAHs in needles and air separate the lighter from the heavier ones. So even if the actual concentrations are not very well described, the temporal air-needles synergies may be better projected by this approach in this particular case.

Finally, spatial correlation coefficients (which provide a simulation for the adequate representation of the BaP spatial patterns over the Iberian Peninsula) are correctly reproduced by all approaches (Table 2). The highest value is seen for winter in approach $2(r=0.68)$ and for the rest of the seasons, approaches 1a-1d present the higher correlation coefficients (from 0.67 in JJA to 0.85 in MAM). Approach 3 generally offers the lowest spatial correlation coefficients for all seasons, except in summer. The fact that the lowest $r$ values are generally found for winter and summer (also the extremes of $\mathrm{BaP}$ concentrations in the environment), highlights the limitations of the model to represent these extremes.

Ideally, the air levels SVOCs are measured in the field using expensive active air sampling equipment which also require permanent power supply while operating. Thus, these devices only exist in certain parts of the world, which does not allow a proper coverage of the global presence of such contaminants, which naturally hinders the efforts of modelling estimation as well. As mentioned above, as living structures vegetation matrices have morphological, physical and chemical behaviour that depends on many parameters, even within the same species. Thus, the equations describing the air-vegetation partition suffer from these effects when a broad solution is searched for. Again in ideal terms, only a direct comparison of field campaigns and active air sampling performed in the same spots is bound to achieve some accuracy, if it includes a seasonal framework as well. In fact, the main approaches presented in this work derive from these types of combined studies. But when it is impossible to have simultaneous active air and biomonitoring sampling models can help us to assess if the assumptions we are working with are sound, if a previous validation with the field-based air concentrations were successful (as is the case in our study). Naturally, there is a concern that the uncertainty associated to all the steps involved may affect the conclusions of a study like this. Even if a detailed analysis were to be extremely complex and out of the scope of this work, the main source of 
Table 2. Results from the comparison of BaP concentrations in air obtained by the chemistry transport models (CTM) simulations and those estimated from levels measured in pine needles by several approaches.

\begin{tabular}{|c|c|c|c|c|}
\hline CTM MEAN* \pm SD $\left(\mathrm{pg} \mathrm{m}^{-3}\right)$ & $\begin{array}{r}\text { DJF } \\
15.63 \pm 15.55 \\
\end{array}$ & $\begin{array}{r}\text { MAM } \\
16.08 \pm 15.48 \\
\end{array}$ & $\begin{array}{r}\text { JJA } \\
7.32 \pm 6.84 \\
\end{array}$ & $\begin{array}{r}\text { SON } \\
11.19 \pm 10.35 \\
\end{array}$ \\
\hline \multicolumn{5}{|c|}{ APPROACH 1a (TEMPORAL CORR. COEF.: 0.51) } \\
\hline & DJF & MAM & JJA & SON \\
\hline SPATIAL CORR. COEF. & 0.57 & 0.85 & 0.67 & 0.80 \\
\hline $\operatorname{MFB}(\%)$ & -125.46 & -129.35 & -125.75 & -136.06 \\
\hline $\operatorname{RMSE}\left(\mathrm{pg} \mathrm{m}^{-3}\right)$ & 19.09 & 16.14 & 8.11 & 14.57 \\
\hline BIAS $\left(\mathrm{pg} \mathrm{m}^{-3}\right)$ & -12.70 & -12.58 & -6.01 & -9.64 \\
\hline METHOD MEAN $\pm \mathrm{SD}\left(\mathrm{pg} \mathrm{m}^{-3}\right)$ & $3.31 \pm 3.24$ & $3.51 \pm 3.21$ & $1.31 \pm 1.01$ & $1.55 \pm 1.21$ \\
\hline \multicolumn{5}{|c|}{ APPROACH 1b (TEMPORAL CORR COEF: 0.51) } \\
\hline & DJF & MAM & JJA & SON \\
\hline SPATIAL CORR. COEF. $(r)$ & 0.57 & 0.85 & 0.67 & 0.80 \\
\hline $\operatorname{MFB}(\%)$ & 198.97 & 198.81 & 198.83 & 198.95 \\
\hline $\operatorname{RMSE}\left(\mathrm{pg} \mathrm{m}^{-3}\right)$ & 12526.82 & 16294.77 & 4413.82 & 5197.87 \\
\hline BIAS $\left(\mathrm{pg} \mathrm{m}^{-3}\right)$ & 9203.00 & 9945.01 & 3815.12 & 4481.39 \\
\hline $\operatorname{METHOD~MEAN~} \pm \mathrm{SD}\left(\mathrm{pg} \mathrm{m}^{-3}\right)$ & $9219 \pm 8358$ & $9961 \pm 9722$ & $3822 \pm 2890$ & $4492 \pm 3424$ \\
\hline \multicolumn{5}{|c|}{ APPROACH 1c (TEMPORAL CORR COEF: 0.51) } \\
\hline & DJF & MAM & JJA & SON \\
\hline SPATIAL CORR. COEF. $(r)$ & 0.57 & 0.85 & 0.67 & 0.80 \\
\hline $\operatorname{MFB}(\%)$ & 193.27 & 192.28 & 193.06 & 193.15 \\
\hline $\operatorname{RMSE}\left(\mathrm{pg} \mathrm{m}^{-3}\right)$ & 1860.48 & 2420.65 & 653.60 & 765.74 \\
\hline BIAS $\left(\mathrm{pg} \mathrm{m}^{-3}\right)$ & 1361.62 & 1474.44 & 563.88 & 660.15 \\
\hline METHOD MEAN $\pm S D\left(\mathrm{pg} \mathrm{m}^{-3}\right)$ & $1377.63 \pm 1347.92$ & $1488.53 \pm 1400.05$ & $571.20 \pm 431.94$ & $671.34 \pm 511.74$ \\
\hline \multicolumn{5}{|c|}{ APPROACH 1d (TEMPORAL CORR COEF: 0.51) } \\
\hline & DJF & MAM & JJA & SON \\
\hline SPATIAL CORR. COEF. $(r)$ & 0.57 & 0.85 & 0.67 & 0.80 \\
\hline $\operatorname{MFB}(\%)$ & 9.21 & -18.99 & -6.30 & -15.58 \\
\hline $\operatorname{RMSE}\left(\mathrm{pg} \mathrm{m}^{-3}\right)$ & 18.34 & 12.42 & 5.91 & 9.45 \\
\hline BIAS $\left(\mathrm{pg} \mathrm{m}^{-3}\right)$ & 0.08 & -0.81 & -0.84 & -2.88 \\
\hline $\operatorname{METHOD~MEAN~} \pm \mathrm{SD}\left(\mathrm{pg} \mathrm{m}^{-3}\right)$ & $15.94 \pm 15.60$ & $15.27 \pm 14.86$ & $6.48 \pm 4.96$ & $8.31 \pm 8.19$ \\
\hline \multicolumn{5}{|c|}{ APPROACH 2 (TEMPORAL CORR COEF: -0.55) } \\
\hline & DJF & MAM & JJA & $\mathrm{SON}$ \\
\hline SPATIAL CORR. COEF. $(r)$ & 0.68 & 0.89 & 0.35 & 0.76 \\
\hline $\operatorname{MFB}(\%)$ & -179.73 & -171.63 & -115.84 & -121.53 \\
\hline $\operatorname{RMSE}\left(\mathrm{pg} \mathrm{m}^{-3}\right)$ & 21.01 & 19.09 & 8.22 & 13.70 \\
\hline BIAS $\left(\mathrm{pg} \mathrm{m}^{-3}\right)$ & -15.33 & -14.96 & -5.81 & -8.89 \\
\hline METHOD MEAN $\pm \mathrm{SD}\left(\mathrm{pg} \mathrm{m}^{-3}\right)$ & $0.68 \pm 0.60$ & $1.13 \pm 1.06$ & $1.51 \pm 1.15$ & $2.30 \pm 2.24$ \\
\hline \multicolumn{5}{|c|}{ APPROACH 3 (TEMPORAL CORR COEF: 0.80) } \\
\hline & DJF & MAM & JJA & SON \\
\hline SPATIAL CORR. COEF. $(r)$ & 0.26 & 0.48 & 0.65 & 0.41 \\
\hline $\operatorname{MFB}(\%)$ & 194.93 & 194.88 & 197.07 & 195.66 \\
\hline $\operatorname{RMSE}\left(\mathrm{pg} \mathrm{m}^{-3}\right)$ & 1212.05 & 1166.83 & 897.97 & 916.64 \\
\hline $\operatorname{BIAS}\left(\mathrm{pg} \mathrm{m}^{-3}\right)$ & 1283.79 & 1214.75 & 967.09 & 986.96 \\
\hline METHOD MEAN $\pm S D\left(\mathrm{pg} \mathrm{m}^{-3}\right)$ & $1299.80 \pm 342.94$ & $1230.83 \pm 333.38$ & $974.41 \pm 36.72$ & $998.15 \pm 41.59$ \\
\hline
\end{tabular}

* Modelling results are considered as a consistent reference to compare the estimations from the different approaches. DJF - December, January and February; MAM - March, April and May; JJA - June, July and August; SON - September, October and November; CTM - chemistry transport model concentrations; SD - standard deviation; CORR COEF - correlation coefficient; MFB - mean fractional bias; RMSE - root mean square error. 
uncertainty of our global process can be identified: the emission inventories for PAHs, as stated by San José et al. (2013). In general, this uncertainty was estimated to be within a factor of 2 to 5 (Berdowski et al., 1997), much larger than any other uncertainty associated with the validation process and rest of steps. For instance, EMEP individual measurements should have a precision within $\pm 10 \%$ and the data quality objectives for the sampling and chemical analysis set a combined uncertainty between 15 and $25 \%$ (EMEP, 2001). Also, the analytical methodology to quantify $\mathrm{BaP}$ in pine needles has similar precision values (Ratola et al., 2009). The contribution of these processes to the global uncertainties would be reduced in comparison to the $\mathrm{BaP}$ emissions.

\section{Conclusions}

This work proved the good performance of pine needles as biomonitors of the $\mathrm{BaP}$ atmospheric concentrations. Results show that the WRF+CHIMERE modelling system reproduces accurately not only the atmospheric presence of $\mathrm{BaP}$, with deviations below $0.4 \mathrm{ng} \mathrm{g}^{-1}$, but also the spatial and temporal patterns of its concentrations over the vegetation in the Iberian Peninsula (biases lower than $30 \%$ for all stations and seasons). From the six methods tested to convert vegetation levels (in pine needles) into atmospheric concentrations, approach 1d showed the most accurate results, followed by approach 1a, when compared to modelling results and observations from EMEP. However, these results should not be interpreted as a ranking of the general performance of the approaches. For instance, given that approaches 1a, 1b, 1c and 1d only differ on the deposition velocity considered for $\mathrm{BaP}$, we can conclude that approach $1 \mathrm{~d}$ is the one representing more closely the particular conditions of the target area. Nevertheless, for other locations and frameworks, further research should be conducted to verify these conclusions. Another very important aspect to take into account is that none of the studies where the available approaches were reported used needles from the same pine species of the current study nor was located in areas of similar climatic or geographical conditions. These facts can considerably alter the uptake conditions of the pollutants, hence the different deposition rates reported.

Arguably, it could be said that when the model is taken as the reference, the deposition velocity in the best approach is not the most adequate for the Iberian Peninsula, but rather the one closer to the approximation of the deposition over vegetal canopies included in the CTM. This suggestion can be rebutted given that the model results were validated against the field data available from the EMEP air sampling stations, proving that the approximation of the model is indeed the most satisfactory for the conditions of this area (and, therefore, so are those of approach 1d). Another unprecedented perspective introduced by this work is that, contrary to the few similar studies found in literature, instead of studying isolated episodes of contamination, the simulations cover a large period (2006-2010). This highlights a climatic viewpoint to the problem of $\mathrm{BaP}$ on a regional scale, and was not done previously (at least over the Iberian Peninsula).

Considering that the theoretical principles of the three methodologies chosen in this work that led to the airvegetation partition calculations are valid worldwide and having some of the parameters missing for our sampling domain, we had to resort to the ones existing in literature. With more similar studies in the future we can head towards a much better reproducibility and robustness of the modelling strategies. Our aim was to open a possible path for it and the results are encouraging. But if fieldwork continues to be as scarce as it is nowadays, the journey will be necessarily slower than we had hoped for.

The relevance of these findings opens the possibility that pine needles can be used to assess the temporal and spatial behaviour of $\mathrm{BaP}$ or other priority pollutants under completely innovating perspectives; namely allowing a reliable understanding of the air quality in areas where common air sampling devices are unavailable. The comparison of levels within a regional scale will enable the strong enhancement of the knowledge available so far in the scientific literature for studies on atmospheric chemistry and transport of transboundary SVOCs, which is scarce (even more if we consider model validation against experimental data). Despite these promising results, further research is still needed and should be devoted to the following: (a) study the applicability of the methods tested to different areas (both geographically and in terms of land use) and (b) assess the performances of different vegetation species and their ability to act as biomonitors of the atmospheric presence of several classes of hazardous compounds.

\section{Information about the Supplement}

Information on pine needles characteristics, sampling, analytical methodology, as well as on the modelling and vegetation-to-air estimation strategies. This material is available in the Supplement free of charge via the Internet.

\section{The Supplement related to this article is available online at doi:10.5194/acp-16-4271-2016-supplement.}

Acknowledgements. This work has been partially funded by the European Union Seventh Framework Programme-Marie Curie COFUND (FP7/2007-2013) under UMU Incoming Mobility Programme ACTion (U-IMPACT) Grant Agreement 267143. The Spanish Ministry of Economy and Competitiveness and the "Fondo Europeo de Desarrollo Regional" (FEDER) are acknowledged for their partial funding (project CGL2014-59677-R), as well as the "Programa Jiménez de la Espada" (ref. 19641/IV/14) from Fundación Séneca - Science and Technology Agency in the Region 
of Murcia.

Edited by: A. Pozzer

\section{References}

Amigo, J. M., Ratola, N., and Alves, A.: Study of geographical trends of polycyclic aromatic hydrocarbons using pine needles, Atmos. Environ., 45, 5988-5996, 2011

Augusto, S., Máguas, C., Matos, J., Pereira, M. J., and Branquinho, C.: Lichens as an integrating tool for monitoring PAH atmospheric deposition: A comparison with soil air and pine needles, Environ. Pollut., 158, 483-489, 2010.

Aulinger, A., Matthias, V., and Quante, M.: An approach to temporally disaggregate benzo $(a)$ pyrene emissions and their application to a 3D Eulerian atmospheric chemistry transport model, Water Air Soil Poll., 216, 643-655, 2011.

Baek, S. O., Field, R. A., Goldstone, M. E., Kirk, P. W., Lester, J. N., and Perry, R.: A review of atmospheric polycyclic aromatic hydrocarbons: sources, fate and behaviour, Water Air Soil Poll., 60, 279-300, 1991.

Barber, J. L., Thomas, G. O., Kerstiens, G., and Jones, K. C.: Current issues and uncertainties in the measurement and modelling of air-vegetation exchange and within-plant processing of POPs, Environ. Pollut., 128, 99-138, 2004.

Baussant, T., Sanni, S., Jonsson, G., Skadsheim, A., and Borseth, J. F.: Bioaccumulation of polycyclic aromatic compounds: 1. Bioconcentration in two marine species and in semipermeable membrane devices during chronic exposure to dispersed crude oil, Environ. Toxicol. Chem., 20, 1175-1184, 2001.

Berdowski, J. J. M., Baas, J., Bloos, J. P. J., Visschedijk, A. J. H., and Zandveld, P. Y. J.: The European Atmospheric Emission Inventory for Heavy Metals and Persistent Organic Pollutants, Umweltforschungsplan des Bundesministers fur Umwelt, Naturschutz und Reaktorsicherheit, Luftreinhaltung. Forschungbericht 10402 672/03, TNO, Apeldoorn, the Netherlands, 1997.

Bernalte, E., Marín-Sánchez, C., Pinilla-Gil, E., Cerceda-Balic, F., and Vidal-Cortex, V.: An exploratory study of particulate PAHs in low-polluted urban and rural areas of southwest Spain: concentrations, source assignment, seasonal variation and correlations with other pollutants, Water Air Soil Poll., 223, 5143-5154, 2012.

Bidleman, T. F.: Atmospheric processes. Wet and dry deposition of organic compounds are controlled by their vapor-particle partitioning, Environ. Sci. Technol., 22, 361-367, 1988.

Bieser, J., Aulinger, A., Matthias, V., and Quante, M.: Impact of emission reductions between 1980 and 2020 on atmospheric benzo $[a]$ pyrene concentrations over Europe, Water Air Soil Poll., 223, 1391-1414, 2012.

Cape, J. N., Paterson, I., and Wolfenden, S. J.: Regional variation in surface properties of Norway spruce and Scots pine needles in relation to forest decline, Environ. Pollut., 58, 325-342, 1989.

Chun, M. Y.: Relationship between PAHs concentrations in ambient air and deposited on pine needles, Environ. Health Toxicol., 26, 6 pp., 2011.

Directive 2008/50/EC of the European Parliament and of the Council of 21 May 2008 on ambient air quality and cleaner air for Europe, Official Journal of the European Union L 152, 1-44, 2008.
EMEP (European Monitoring and Evaluation Programme): EMEP manual for sampling and chemical analysis. EMEP/CCC-Report 1/1995 - revised, Norwegian Institute for Air Research, Kjeller, Norway, November 2001.

Friedman, C. L. and Selin, N. E.: Long-range atmospheric transport of polycyclic aromatic hydrocarbons: a global 3-D model analysis including evaluation of Arctic sources, Environ. Sci. Technol., 46, 9501-9510, 2012.

Galarneau, E., Makar, P. A., Zheng, Q., Narayan, J., Zhang, J., Moran, M. D., Bari, M. A., Pathela, S., Chen, A., and Chlumsky, R.: PAH concentrations simulated with the AURAMS-PAH chemical transport model over Canada and the USA, Atmos. Chem. Phys., 14, 4065-4077, doi:10.5194/acp-14-4065-2014, 2014.

Giorgi, F.: A particle dry deposition scheme for use in tracer transport models, J. Geophys. Res., 91, 9794-9806, 1986.

Horstmann, M. and McLachlan, M. S.: Atmospheric deposition of semivolatile organic compounds to two forest canopies, Atmos. Environ., 32, 1799-1809, 1998.

Hwang, H. H. and Wade, T. L.: Aerial distribution, temperaturedependent seasonal variation, and sources of polycyclic aromatic hydrocarbons in pine needles from the Houston metropolitan area, Texas, USA, J. Environ. Sci. Heal. A, 43, 1243-1251, 2008.

Jakeman, A. J., Letcher, R. A., and Norton, J. P.: Ten iterative steps in development and evaluation of environmental models, Environ. Modell. Soft., 21, 602-614, 2006.

Jiménez-Guerrero, P., Jorba, O., Baldasano, J. M., and Gassó, S.: The use of a modelling system as a tool for air quality management: annual high-resolution simulations and evaluation, Sci. Total Environ., 390, 323-340, 2008.

Klánová, J., Čupr, P., Baráková, D., Šeda, Z., Anděl, P., and Holoubek, I.: Can pine needles indicate trends in the air pollution levels at remote sites?, Environ. Pollut., 157, 3248-3254, 2009.

Lammel, G., Sehili, A. M., Bond, T. C., Feichter, J., and Grassl, H.: Gas/particle partitioning and global distribution of polycyclic aromatic hydrocarbons - a modelling approach, Chemosphere, 76, 98-106, 2009.

Lehndorff, E. and Schwark, L.: Biomonitoring airborne parent and alkylated three-ring PAHs in the Greater Cologne Conurbation II: Regional distribution patterns, Environ. Pollut., 157, 1706-1713, 2009.

Mackay, D.: Multimedia Environmental Models: the Fugacity Approach, Lewis Pub., Chelsea, MI, 1991.

Maddalena, R. L., McKone, T. E., and Riley, W. J.: Is there a "forest filter effect” for organic pollutants?, Stoch. Env. Res. Risk A., 17, 231-234, 2003.

Mastral, A. M. and Callén, M. S.: A review on polycyclic aromatic hydrocarbon (PAH) emission from energy generation, Environ. Sci. Technol., 34, 3051-3057, 2000.

Matthias, V., Aulinger, A., and Quarte, M.: CMAQ simulations of the benzo(a)pyrene distribution over Europe for 2000 and 2001, Atmos. Environ., 43, 4078-4086, 2009.

Menut, L., Bessagnet, B., Khvorostyanov, D., Beekmann, M., Blond, N., Colette, A., Coll, I., Curci, G., Foret, G., Hodzic, A., Mailler, S., Meleux, F., Monge, J.-L., Pison, I., Siour, G., Turquety, S., Valari, M., Vautard, R., and Vivanco, M. G.: CHIMERE 2013: a model for regional atmospheric composition 
modelling, Geosci. Model Dev., 6, 981-1028, doi:10.5194/gmd6-981-2013, 2013.

Morville, S., Delhomme, O., and Millet, M.: Seasonal and diurnal variations of PAH concentrations between rural, suburban and urban areas, Atmos. Pollut. Res., 2, 366-373, 2011.

Odabasi, M., Cetin, E., and Sofuoglu, A.: Determination of octanolair partition coefficients and supercooled liquid vapor pressures of PAHs as a function of temperature: Application to gas-particle partitioning in an urban atmosphere, Atmos. Environ., 40, 66156625, 2006.

Peters, K. and Eiden, R.: Modelling the dry deposition velocity of aerosol particles to a spruce forest, Atmos. Environ., 26, 25552564, 1992.

Piccardo, M. T., Pala, M., Bonaccurso, B., Stella, A., Redaelli, A., Paola, G., and Valério, F.: Pinus nigra and Pinus pinaster needles as passive samplers of polycyclic aromatic hydrocarbons, Environ. Pollut., 133, 293-301, 2005.

Pöschl, U., Letzel, T., Schauer, C., and Niessner, R.: Interaction of ozone and water vapor with spark discharge soot aerosol particles coated with benzo[ $[a]$ pyrene: $\mathrm{O}_{3}$ and $\mathrm{H}_{2} \mathrm{O}$ adsportion, benzo $[a]$ pyrene degradation, and atmospheric implications, J. Phys. Chem. A, 105, 4029-4041, 2001.

Ratola, N. and Jiménez-Guerrero, P.: Combined field/modelling approaches to represent the air-vegetation distribution of benzo $[a]$ pyrene using different vegetation species, Atmos. Environ., 106, 34-42, 2015.

Ratola, N., Lacorte, S., Barceló, D., and Alves, A.: Microwaveassisted extraction and ultrasonic extraction to determine polycyclic aromatic hydrocarbons in needles and bark of Pinus pinaster Ait. and Pinus pinea L. by GC-MS, Talanta, 77, 11201128, 2009.

Ratola, N., Amigo, J. M., and Alves, A.: Comprehensive assessment of pine needles as bioindicators of PAHs using multivariate analysis. The importance of temporal trends, Chemosphere, 81, 1517-1525, 2010a.

Ratola, N., Amigo, J. M., and Alves, A.: Levels and sources of PAHs in selected sites from Portugal: biomonitoring with Pinus pinea and Pinus pinaster needles, Arch. Environ. Con. Tox., 58, 631-647, 2010b.

Ratola, N., Amigo, J. M., Oliveira, M. S. N., Araújo, R., Silva, J. A., and Alves, A.: Differences between Pinus pinea and Pinus pinaster as bioindicators of polycyclic aromatic hydrocarbons, Environ. Exp. Bot., 72, 339-347, 2011.

Ratola, N., Alves, A., Lacorte, S., and Barceló, D.: Distribution and sources of PAHs using three pine species along the Ebro river, Environ. Monit. Assess., 184, 985-999, 2012.

San José, R., Pérez, J. L., Callén, M. S., López, J. M., and Mastral, A.: BaP (PAH) air quality modelling exercise over Zaragoza (Spain) using an adapted version of WRF-CMAQ model, Environ. Pollut., 183, 151-158, 2013.

Schwarzenbach, R. P., Gschwend, P. M., and Imboden, D. M.: Environmental Organic Chemistry, 2nd Edn., John Wiley \& Sons, Hoboken, New Jersey, 2003.
Sehili, A. M. and Lammel, G.: Global fate and distribution of polycyclic aromatic hydrocarbons emitted from Europe and Russia, Atmos. Environ., 41, 8301-8315, 2007.

Seinfeld, J. H. and Pandis, S. N.: Atmospheric Chemistry and Physics: from Air Pollution to Climate Change, Wiley- Interscience, New Jersey, 1997.

Simonich, S. and Hites, R.: Vegetation-atmosphere partitioning of polycyclic aromatic hydrocarbons, Environ. Sci. Technol., 28, 939-943, 1994.

Skamarock, W. C., Klemp, J. B., Dudhia, J., Gill, D. O., Barker, D. M., and Duda, M. G.: A description of the Advanced Research WRF Version 3, NCAR technical note NCAR/TN20201c475+STR, http://www2.mmm.ucar.edu/wrf/ users/docs/arw_v3.pdf (last access: on 29 January 2016), 2008.

Solé, M.: Assessment of the results of chemical analyses combined with the biological effects of organic pollution on mussels, Trend. Anal Chem., 19, 1-8, 2000.

St-Amand, A. D., Mayer, P. M., and Blais, J. M.: Modeling atmospheric vegetation uptake of PBDEs using field measurements, Environ. Sci. Technol., 41, 4234-4239, 2007.

St-Amand, A. D., Mayer, P. M., and Blais, J. M.: Modeling PAH uptake by vegetation from the air using field measurements, Atmos. Environ., 43, 4283-4288, 2009a.

St-Amand, A. D., Mayer, P. M., and Blais, J. M.: Prediction of SVOC vegetation and atmospheric concentrations using calculated deposition velocities, Environ. Int., 35, 851-855, $2009 \mathrm{~b}$.

Tomashuk, T. A.: A comparison of atmospheric PAHs in pine needles and high-volume sampler filters in the Dayton metro area, MS Thesis, Wright State University, Dayton OH, 83 pp., 2010.

Tørseth, K., Aas, W., Breivik, K., Fjæraa, A. M., Fiebig, M., Hjellbrekke, A. G., Lund Myhre, C., Solberg, S., and Yttri, K. E.: Introduction to the European Monitoring and Evaluation Programme (EMEP) and observed atmospheric composition change during 1972-2009, Atmos. Chem. Phys., 12, 5447-5481, doi:10.5194/acp-12-5447-2012, 2012.

Tremolada, P., Burnett, V., Calamari, D., and Jones, K. C.: Spatial distribution of PAHs in the UK atmosphere using pine needles, Environ. Sci. Technol., 30, 3570-3577, 1996.

Vestreng, V., Ntziachristos, L., Semb, A., Reis, S., Isaksen, I. S. A., and Tarrasón, L.: Evolution of $\mathrm{NO}_{\mathrm{x}}$ emissions in Europe with focus on road transport control measures, Atmos. Chem. Phys., 9, 1503-1520, doi:10.5194/acp-9-1503-2009, 2009.

Weiss, P., Lorbeer, G., and Scharf, S.: Regional aspects and statistical characterisation of the load with semivolatile organic compounds at remote Austrian forest sites, Chemosphere, 40, 11591171, 2000.

Wesely, M.: Parameterization of surface resistances to gaseous dry deposition in regional scale numerical models, Atmos. Environ., 23, 1293-1304, 1989.

Zhang, L., Gong, S., Padro, J., and Barrie, L.: A size-segregated particle dry deposition scheme for an atmospheric aerosol module, Atmos. Environ., 35, 549-560, 2001. 